\title{
Numerical Simulation and Experimental Study on Temperature Distribution of Self-Lubricating Packing Rings in Reciprocating Compressors
}

\author{
Jia Xiaohan, Zhang Qingqing, Feng Jianmei, and Peng Xueyuan \\ Xian Jiaotong University, Xian, China \\ Correspondence should be addressed to Peng Xueyuan; xypeng@xjtu.edu.cn
}

Received 26 April 2016; Accepted 23 August 2016

Academic Editor: Roman Wendner

Copyright ( 2016 Jia Xiaohan et al. This is an open access article distributed under the Creative Commons Attribution License, which permits unrestricted use, distribution, and reproduction in any medium, provided the original work is properly cited.

\begin{abstract}
The nonuniform abrasion failure and high-temperature thermal failure of packing rings have a significant influence on compressor reliability, particularly that of oil-free compressors. In this study, a test rig was constructed to measure the dynamic temperature of packing rings under different operational conditions in an oil-free reciprocating compressor. The dynamic axial and radial temperature distributions of the packing rings were obtained using an innovative internal temperature testing device that kept the thermocouples and packing box relatively static during compressor operation. A three-dimensional heat transfer model was also developed to analyze the temperature distribution of the packing boxes, piston rod, and cylinder during such operation. Good agreement was observed between the simulation results and experimental data, which showed an average relative error of less than $2.35 \%$. The results indicate that the pressure ratio exerts a significant effect on the axial temperature distribution and determines which packing ring reaches the maximum temperature. They also show the average temperature to rise with an increase in the rotational speed and to fall with an improvement in the external cooling conditions. Finally, the material of the packing rings was found to affect the temperature gradient from their inner to outer surface.
\end{abstract}

\section{Introduction}

Packing rings are widely used in reciprocating compressors, and their sealing performance has a significant influence on both compressor performance and reliability, particularly those of oil-free compressors. The nonuniform abrasion failure and high-temperature thermal failure of packing rings occur frequently in oil-free compressors in high-temperature and -pressure conditions. In investigating these issues, many researchers have focused on such friction characteristics as self-lubrication and stress distribution and the principles of friction wear.

Plastic is often used as a self-lubricating material in packing rings and piston rings, which have a similar function to packing rings. Polytetrafluoroethylene (PTFE) has a lower friction coefficient and great self-lubricating properties, but the low wear resistance is huge disadvantage for usage as packing rings. But filling carbon fiber into the PTFE could improve the wear performance of PTFE significantly. Hence, some researchers have examined the degree of friction between plastic and metal $[1,2]$. Radcliffe [3] extended the life of the self-lubricating properties of filled PTFE materials through the careful formulation and selection of filler materials. Kowandy et al. [4] found correlations between the characteristics of the wear particles, coefficients of friction, and wear rates of three types of PTFE (pure and glass fiberand carbographite-filled) to determine the wear mechanisms. Zhu et al. [5] formulated a high-temperature, self-lubricating composite, NiAl-Cr-Mo-CaF2, for piston rings and found it to have a favorable friction coefficient of about 0.2. Okularczyk [6] set up a stuffing box (packing box) packing test in a water hydraulic system and obtained variable friction coefficients for guide rings made of a PTFE composite when the piston rod velocity was altered.

The pressure and stress distributions of packing and piston rings have also attracted considerable research attention in the past decade. Xin et al. [7] investigated their dynamic pressure distribution using theoretical and experimental 
methods. Their results showed the first ring to bear more than $75 \%$ of the total pressure, which was the main reason for the nonuniform wear and resulting early failure. Pengyun et al. [8] presented theoretical analysis of the relationship between two lateral pressure coefficients, that between the packing and stem and that between the packing and housing, in a soft-packed stuffing box seal and demonstrated the theorized relationship with experimental data. Diany and Bouzid $[9,10]$ proposed a simplified analytical approach using the theory behind thick-walled cylinders to investigate the stresses and displacements in stuffing box systems. Their model suggested a contact pressure ratio close to 1 and indicated that the interface contact pressure depends on several parameters. Kazeminia and Bouzid [11-13] presented several analytical models for investigating the stresses and strains on stuffing box components, including packing rings, two of which can be applied to improve valve seal performance. Girão and Guenther [14] and Veiga et al. [15] used a simulated stuffing box test device to measure the protocol; radial and axial forces associated with the thermal stresses of different packing configurations. They showed that packing expansion due to temperature variations can greatly increase the internal stresses in a stuffing box, leading to high shaft torque and the eventual scorching of the packing.

Several studies have been carried out to gain a general understanding of packing ring friction wear [16-18]. Obert et al. [19] developed a reciprocating model test that reproduced the real load situation of the contact condition between the piston ring and cylinder liner at the fired top dead center. They tested friction, wear, and scuffing and found the loadcarrying capacity to be heavily dependent on temperature and the oil supply rate. Johansson et al. [20, 21] developed reliable test methods for evaluating the frictional difference between different material combinations/surfaces and used them to test the interaction of dynamic viscosity, velocity, and contact pressure. There is also a considerable body of research on heat transfer in the cylinders of reciprocating compressors $[22,23]$. Shen et al. [24] used a three-dimensional (3D) finite element model to investigate the heat transfer process in the cylinder of a boil-off gas compressor, a type of oil-free reciprocating compressor. Simulations of the temperature change in the cylinder's inner surface showed more than $60 \%$ of the total temperature decline to occur within the first ten minutes of compressor operation.

Although many of the influence factors of packing rings and packing boxes have been investigated [25], few studies have focused on friction heat transfer or clearly presented the temperature distribution of packing rings, particularly their dynamic temperature distribution. In the study reported herein, a 3D heat transfer model was developed to determine the temperature distribution inside the packing rings of an oil-free reciprocating compressor. An innovative temperature testing device placed inside the packing rings, which kept the thermocouples and packing box relatively static during compressor operation, was designed to obtain the dynamic axial and radial temperature distributions. The effects of pressure ratio, rotational speed, external cooling conditions, and packing ring material on the temperature distributions are discussed in detail.

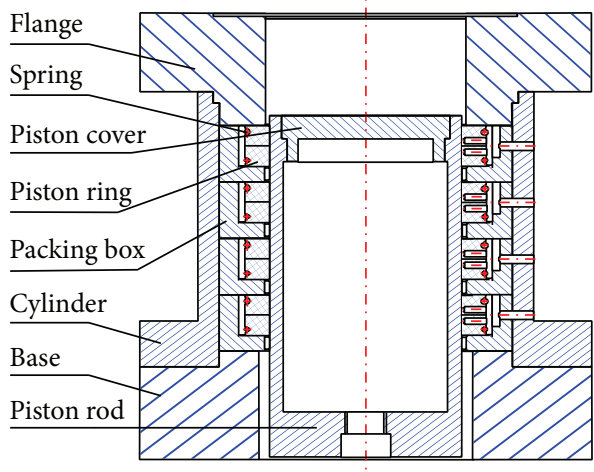

FIGURE 1: Packing rings in the reciprocating compressor under study.

\section{Numerical Simulation}

2.1. Basic Assumptions. Figure 1 is a diagram of the packing rings in the reciprocating compressor investigated in this study. The packing rings were installed between the cylinder and piston rod to prevent high-pressure gas leakage in the direction of the piston rod during reciprocating motion. The packing box featured several grooves, each of which held two rings: a radially cut ring (facing the high-pressure side) and a tangent cut ring. In this setup, the ring nearest the cylinder carries almost the entire pressure load, and when the ring wears or changes for any reason, the load shifts to one of the other rings. The number of rings in a setup influences the packing life but has little effect on leakage. In contrast to the mechanism whereby the outer surface of the piston rings is in contact with the inner surface of the cylinder and the rings move together with the piston in reciprocating motion, in this study's setup the packing rings connected with the piston rod on the inner surface and did not move in conjunction with the piston. Frictional heat has a significant effect on the temperature distribution of packing rings. There are four means by which heat is exchanged during compressor operation. The first is via forced convection heat transfer, which occurs between the compressed gas and inner surface of the cylinder. The second is heat exchange through the frictional heat generated and conducted between the packing rings and outer surface of the piston rod. The third is via natural convection heat transfer, which takes place between the ambient air and outer surface of the cylinder. The fourth and final means of heat exchange is thermal conduction among the cylinder, piston rod, and crankcase. Although the aforementioned thermodynamic processes are unsteady, the temperature distribution of the packing rings becomes steady under stable compressor operation. Thus, heat exchange was considered to be in the steady state in this study.

The following conditions were set in modeling the thermodynamic processes of the packing rings.

(1) The properties of the cylinder materials were homogeneous in all conditions. 
(2) The friction coefficient between the piston rings and cylinder was constant, and all frictional work was converted into heat.

(3) The contact thermal resistance between the packing rings and piston rod was ignored, as was the contact thermal resistance between the external surface of the packing box and inner surface of the cylinder.

(4) The low-pressure side of the packing rings was in contact with the packing box at all points.

(5) The effect of holes and chamfers was ignored.

2.2. Fundamental Equations. The frictional heat flux during friction progress can be calculated as [26]

$$
q=\mu_{f} p v
$$

where $p$ is normal pressure and $v$ is relative velocity, both of which are periodic values. Frictional heat flux can also be considered a periodic value with time $q=q(t)$ or crank angle $q=q(\theta)$.

The heat transfer between the packing rings and piston is based on the heat conduction differential equation, which can be expressed as

$$
\begin{aligned}
\rho c_{p} \frac{\partial T}{\partial \tau}= & \dot{\Phi}+\frac{\partial}{\partial x}\left(\lambda_{x x} \frac{\partial T}{\partial x}\right)+\frac{\partial}{\partial y}\left(\lambda_{y y} \frac{\partial T}{\partial y}\right) \\
& +\frac{\partial}{\partial z}\left(\lambda_{z z} \frac{\partial T}{\partial z}\right) .
\end{aligned}
$$

The energy balance equation in a steady thermal system is

$$
[K]\{T\}=\{Q\},
$$

where $[K]$ is the conduction matrix comprising the thermal, convection, radiation, and shape coefficients; $\{T\}$ is the node vector of temperature; and $\{Q\}$ is the node vector of heat flux, which includes heat generation.

2.3. Boundary Conditions. The four following boundary conditions were considered during the compressor's working process.

(1) Heat Convection in the Working Chamber. Heat convection in the working chamber was regarded as the first boundary condition. Therefore, the temperature of the surrounding fluid and convective heat transfer coefficient $h_{w}$ were calculated. Heat convection stabilized after the steady operation of the compressor. The gas temperature and pressure changed with the crank angle and were determined by the internal thermal transfer in the compressor. Heat convection is a complex physical phenomenon, and the convective heat transfer coefficient is a numerical expression of that complexity. In this study, the convective heat transfer coefficient of the reciprocating compressor was calculated by the same method as that used for internal combustion engines, which are another type of reciprocating machinery. In an oil-free compressor, the temperature and pressure of the gas have a significant influence on $h_{w}$ and on piston velocity. Thus, according to the Woschni equation [27], the heat transfer coefficient can be expressed as

$$
h_{w}=2817 \times D^{-0.214} \times\left(V_{p} \times p_{i}\right)^{0.786} \times T_{i}^{-0.525},
$$

where $D$ is the cylinder diameter, $V_{p}$ is the average velocity of the piston, and $p_{i}$ and $T_{i}$ are the gas pressure and temperature in the working chamber.

(2) Frictional Heat Transfer. Frictional heat is generated within the friction pair (i.e., the packing rings and piston rod) and is regarded as an unsteady reciprocating heat source. Hence, heat transfer on the frictional surface was treated as the second boundary condition. The pressure in the normal direction was calculated first, and then the frictional heat flux in one cycle was calculated using (1). The partition coefficient determines how much heat is transferred to the piston and packing ring sides. It can be obtained by (5), which considers not only the material property but also the friction area and temperature increase within the friction pair:

$$
\begin{aligned}
\gamma & =\frac{q_{2}}{q_{1}+q_{2}} \\
& =\frac{1}{1+\left(\theta_{1} / \theta_{2}\right)\left(A_{1} / A_{2}\right) \sqrt{\lambda_{1} c_{p 1} \rho_{1} / \lambda_{2} c_{p 2} \rho_{2}}},
\end{aligned}
$$

where $\gamma$ is the heat partition coefficient indicating the heat flux ratio of the packing rings to the total heat, $q$ is the heat flux, $\theta$ is the surface temperature rise, $A$ is the area, and subscripts 1 and 2 indicate the piston rod and packing rings, respectively.

(3) Natural Convection Heat Transfer. The third boundary condition was the natural convection heat transfer, which remains stable when the ambient temperature remains unchanged. In this study, the convective heat transfer coefficients were $10 \mathrm{~W} \cdot \mathrm{m}^{-2} \cdot \mathrm{K}^{-1}, 50 \mathrm{~W} \cdot \mathrm{m}^{-2} \cdot \mathrm{K}^{-1}$, and $100 \mathrm{~W} \cdot \mathrm{m}^{-2} \cdot \mathrm{K}^{-1}$ when the system was operated in natural cooling, $1880 \mathrm{~m}^{3} \cdot \mathrm{h}^{-1}$ wind cooling, and $3000 \mathrm{~m}^{3} \cdot \mathrm{h}^{-1}$ wind cooling conditions, respectively. Ambient temperature could be set as a known boundary condition to gain more accurate results.

(4) Contact Heat Conduction with the Crankcase. When a compressor operates stably, the temperature in the crankcase can be considered a constant. Thus, the contact heat conduction among the cylinder, piston rod, and crankcase was regarded as the fourth and final boundary condition in this study. To increase computational accuracy, the temperature of the contact surface between the cylinder and crankcase could also be regarded as known boundary condition.

2.4. Finite Element Model. The 3D model used in this research is pictured in Figure 2. The packing boxes, piston rod, and cylinder were integrated as the object of analysis. A 3D heat transfer model was developed to analyze the temperature distribution. It was meshed using the ten-node tetrahedral element, which was deemed the most suitable for the $3 \mathrm{D}$ thermal analysis of static and transient states. 


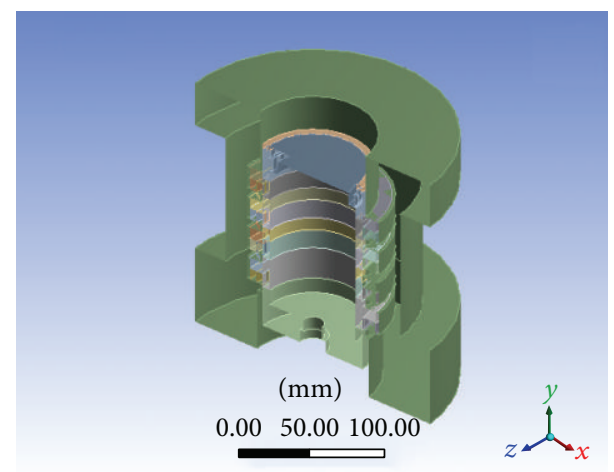

FIGURE 2: 3D model of packing boxes, piston rod, and cylinder.

TABLE 1: Features of the compressor.

\begin{tabular}{lccc}
\hline $\begin{array}{l}\text { Crank radius } \\
(\mathrm{mm})\end{array}$ & $\begin{array}{c}\text { Ratio of } \\
\text { crank to rod }\end{array}$ & $\begin{array}{c}\text { Rotational } \\
\text { speed }\left(\mathrm{r} \cdot \mathrm{min}^{-1}\right)\end{array}$ & $\begin{array}{c}\text { Angular velocity } \\
\left(\mathrm{rad} \cdot \mathrm{s}^{-1}\right)\end{array}$ \\
\hline 20 & 2 & 1450 & 152 \\
\hline
\end{tabular}

TABLE 2: Main structure size of the packing rings ( $\mathrm{mm}$ ).

\begin{tabular}{lcccc}
\hline Structure & $\begin{array}{c}\text { Inner } \\
\text { diameter }\end{array}$ & $\begin{array}{c}\text { Outer } \\
\text { diameter }\end{array}$ & Height & Cut width \\
\hline Radially cut ring & 85 & 107 & 9 & 3 \\
Tangent cut ring & 85 & 107 & 9 & 3 \\
\hline
\end{tabular}

TABLE 3: Main structure size of the piston $\operatorname{rod}(\mathrm{mm})$.

\begin{tabular}{lcc}
\hline Structure & Outer diameter & Height \\
\hline Piston rod & 85 & 151 \\
\hline
\end{tabular}

TABLE 4: Material physical properties.

\begin{tabular}{lcc}
\hline Parameters & $\# 45$ steel & Carbon fiber-filled PTFE \\
\hline$\rho\left(\mathrm{kg} \cdot \mathrm{m}^{-3}\right)$ & 7850 & 2040 \\
$\lambda\left(\mathrm{W} \cdot \mathrm{m}^{-1} \mathrm{~K}^{-1}\right)$ & 64.8 & 0.5 \\
$c_{p}\left(\mathrm{~J} \cdot \mathrm{kg}^{-1} \mathrm{~K}^{-1}\right)$ & 468 & 1050 \\
Poisson ratio & 0.3 & 0.4 \\
Elasticity modulus & $210 \mathrm{G}$ & $800 \mathrm{M}$ \\
Linear expansion & $1.16 e^{-6}$ & $1 e^{-4}$ \\
coefficient & &
\end{tabular}

The main geometric parameters of the oil-free compressor under study, including the packing rings and piston rod, are presented in Tables 1-3. The material used for the piston rod, packing box, and cylinder was \#45 steel, and the packing rings were made of carbon fiber-filled PTFE. Table 4 gives the physical properties of the two materials.

A grid independence study was performed by comparing the simulation results obtained under the different grid numbers shown in Table 5. It can be seen from Figure 3 that the temperature distributions of the three models with differing grid numbers were identical. Their maximum temperatures were $102.22^{\circ} \mathrm{C}, 102.35^{\circ} \mathrm{C}$, and $102.27^{\circ} \mathrm{C}$. The difference between the results for coarser and finer grids
TABLE 5: Grid independence study.

\begin{tabular}{|c|c|c|c|}
\hline \multirow{2}{*}{ Model } & \multicolumn{3}{|c|}{ Grid numbers } \\
\hline & Piston rod & Packing rings & Packing box \\
\hline Model 1 & 8682 & 30903 & 70670 \\
\hline Model 2 & 49757 & 192697 & 495630 \\
\hline Model 3 & 323658 & 1470814 & 3763725 \\
\hline
\end{tabular}

was less than $0.05 \%$, suggesting that grid independence can be achieved with coarser mesh. However, to eliminate any uncertainty, the simulations were performed using a medium grid.

\section{Experimental Investigation}

3.1. Test Rig. To validate the heat transfer model, the temperature distribution inside the packing rings of an oil-free compressor was also investigated experimentally using the test rig shown in Figure 4. The original test compressor's flow rate was $0.33 \mathrm{~m}^{3} \cdot \mathrm{min}^{-1}$, and the discharge pressure in the first and second stages was $0.7 \mathrm{MPa}$ and 5.0 $\mathrm{MPa}$, respectively. Several modifications were made to measure the temperature distribution inside the packing rings. The piston, suction, and discharge valves were removed in the first stage to keep them from working during the tests, and the innovatively designed piston and packing box were installed in the second stage.

An innovative device for testing the dynamic temperature distribution inside the packing rings was designed to measure the interface temperature between the packing rings and piston rod. Figures 5(a) and 5(b) show the appearance and structure of that device. To measure the dynamic temperature distribution along the axial direction between the packing rings and piston rod, thermocouples were placed at points 1 to 8 , where the depth of the mounting hole was $10.5 \mathrm{~mm}$ (the thickness of the packing rings was $11 \mathrm{~mm}$ ). To measure the temperature distribution along the radial direction, a group of thermocouples was arranged at the two positions of the packing rings, as shown in Figure 6, where the depth of position 1-1 was $6 \mathrm{~mm}$. Several fabrication holes along the radial direction were punched in the corresponding positions of the packing box and the cylinder to bring the thermocouples out. The thermocouples and packing box remained relatively static when the piston rod underwent reciprocating motion during compressor operation. This experimental setup allowed the dynamic temperature of the packing ring surface in different working conditions to be obtained.

3.2. Uncertainty Analysis. According to uncertainty theory [28], the combined standard uncertainty in a measurement is the positive square root of the variance:

$$
u_{c}^{2}(y)=\sum_{i=1}^{n}\left(\frac{\partial f}{\partial x_{i}}\right)^{2} u^{2}\left(x_{i}\right)
$$

where $u\left(x_{i}\right)$ represents the uncertainty of the calculated quantity and $x_{i}$ is the uncertainty of the individual measurements.

In this experiment, the combined uncertainty was associated primarily with the uncertainties of the thermocouple 


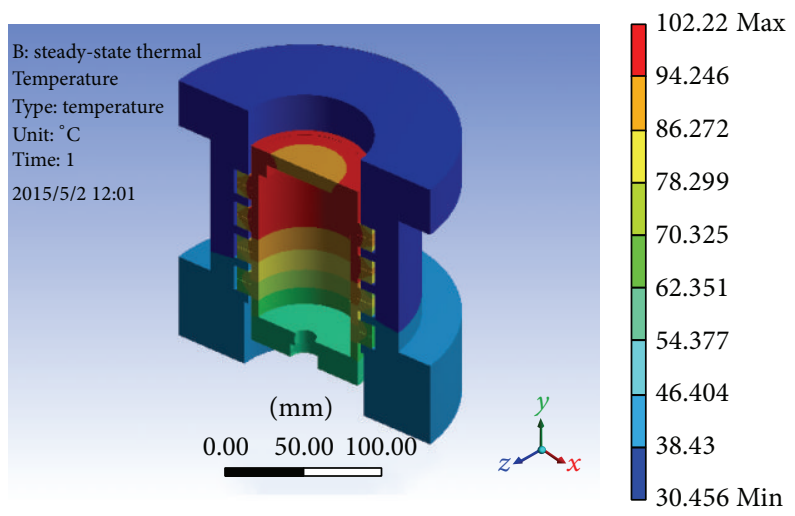

(a) Model 1

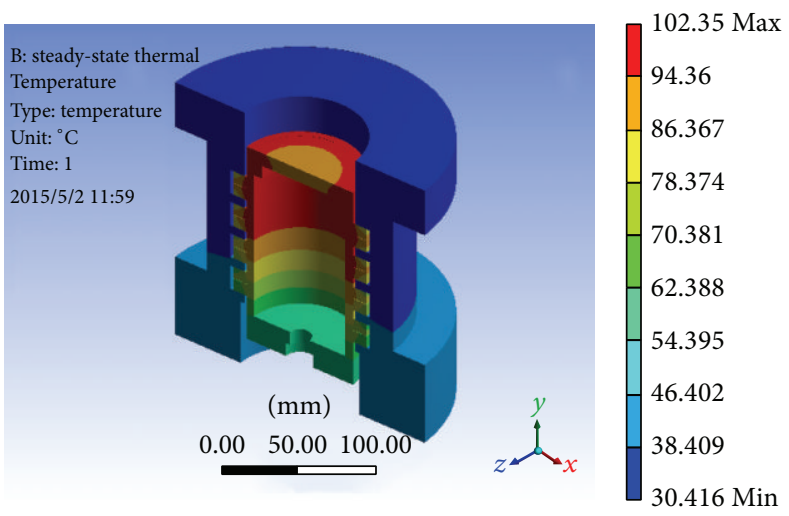

(b) Model 2

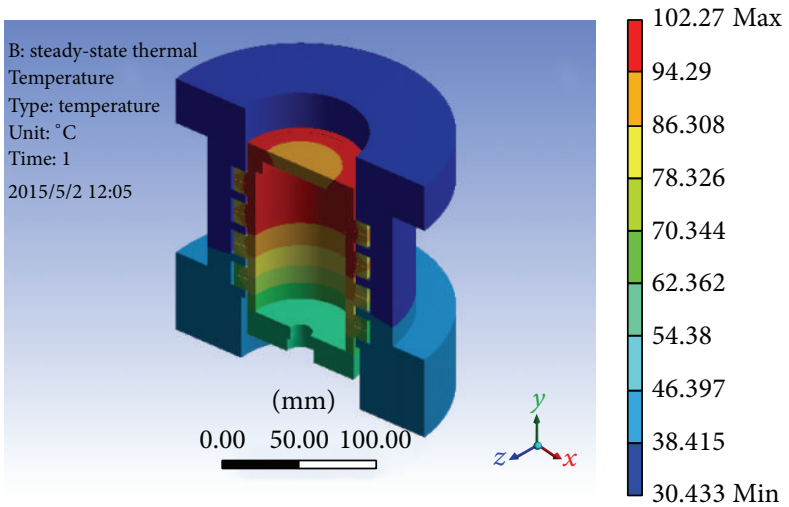

(c) Model 3

FIGURE 3: Temperature distribution of modeling results.

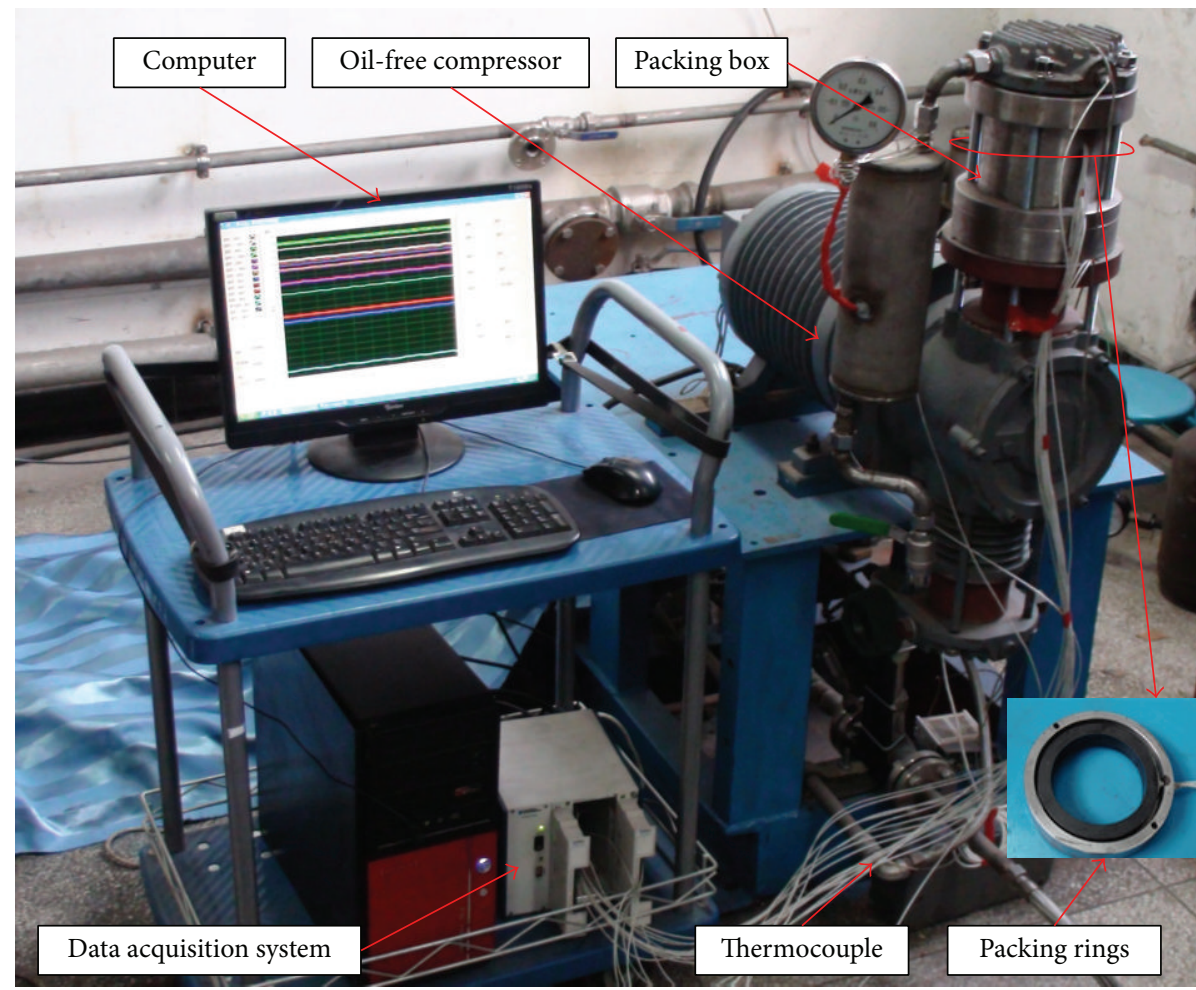

FIGURE 4: Test rig of the oil-free compressor system. 


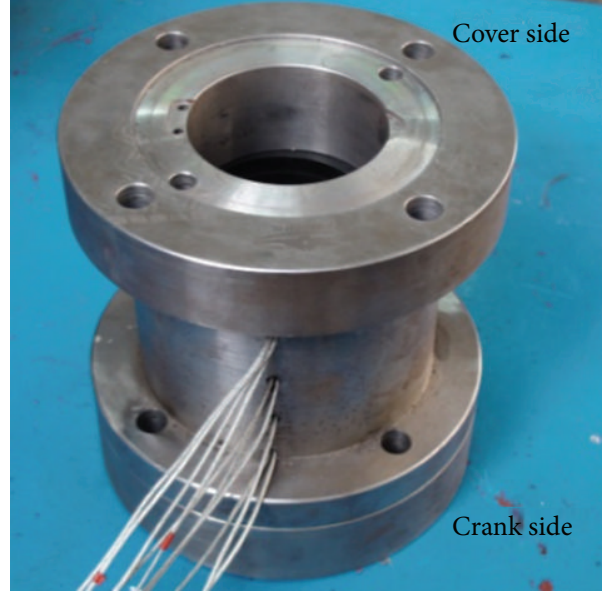

(a)

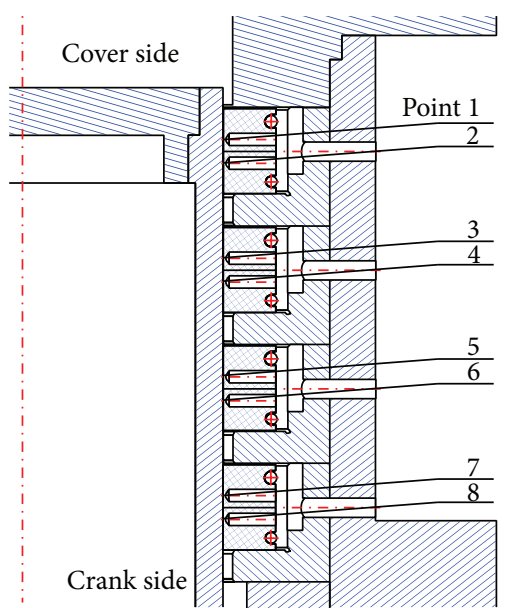

(b)

FIGURE 5: Appearance and structure of the designed device.

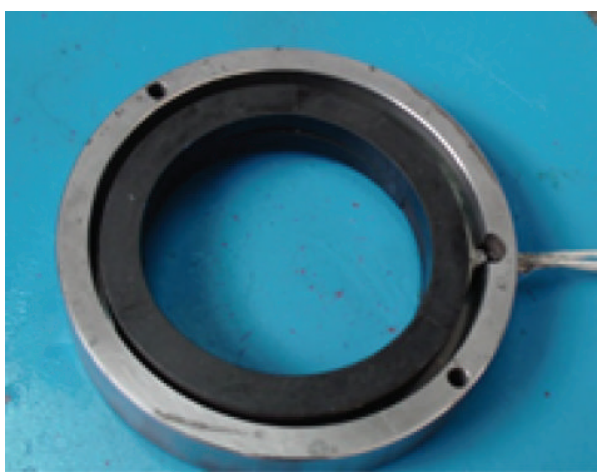

(a)

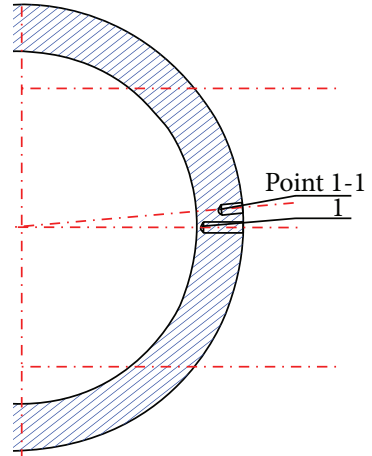

(b)

FIGURE 6: Thermocouple arrangement.

and data acquisition system, which were less than $0.1 \%$ and $0.001 \%$, respectively, and thus the combined uncertainty was about $0.10 \%$.

\section{Results and Discussion}

Four groups of working conditions were applied to analyze the dynamic temperature distribution of the packing rings in an oil-free reciprocating compressor via numerical simulation and experimental investigation. As shown in Table 6, groups A, B, C, and D were used to analyze the influences of the compressor's rotational speed, pressure ratio, cooling wind speed, and discharge temperature distribution of the packing rings.

\subsection{Model Validation}

4.1.1. Axial Temperature Distribution. The temperature distribution in the direction of the axle was validated by comparing the simulated results and experimental data under conditions B3 and C1. As shown in Figure 7, both the theoretical and experimental results show a gradual decrease in temperature from points 1 to 8 . One possible explanation for this decrease
TABLE 6: Simulation and experiment conditions.

\begin{tabular}{lcccc}
\hline Condition & $\begin{array}{c}\text { Cooling wind } \\
\text { speed } \\
\left(\mathrm{m}^{3} \cdot \mathrm{h}^{-1}\right)\end{array}$ & $\begin{array}{c}\text { Pressure } \\
\text { ratio }\end{array}$ & $\begin{array}{c}\text { Discharge } \\
\text { temperature } \\
(\mathrm{K})\end{array}$ & $\begin{array}{c}\text { Rotational } \\
\text { speed } \\
\left(\mathrm{r} \cdot \mathrm{min}^{-1}\right)\end{array}$ \\
\hline A1 & 1880 & 1.0 & - & 580 \\
$\mathrm{~A} 2$ & 1880 & 1.0 & - & 1015 \\
$\mathrm{~A} 3$ & 1880 & 1.0 & - & 1450 \\
$\mathrm{~B} 1$ & 1880 & 1.0 & - & 1450 \\
$\mathrm{~B} 2$ & 1880 & 1.8 & - & 1450 \\
$\mathrm{~B} 3$ & 1880 & 2.6 & - & 1450 \\
$\mathrm{C1}$ & Natural & 2.6 & - & 1450 \\
$\mathrm{C} 2(\mathrm{~B} 3)$ & 1880 & 2.6 & - & 1450 \\
$\mathrm{C} 3$ & 3000 & 2.6 & - & 1450 \\
D1 & 1880 & - & 291.05 & 1450 \\
$\mathrm{D} 2$ & 1880 & - & 329.25 & 1450 \\
D3 & 1880 & - & 346.15 & 1450 \\
\hline
\end{tabular}

is that the boundary condition of forced convection heat transfer between the high-temperature compressed gas and 


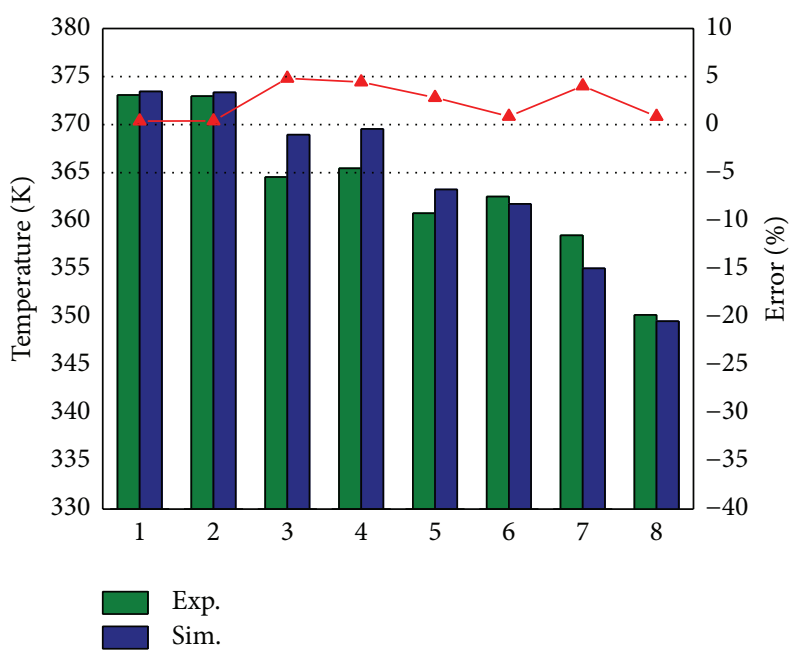

(a) B3

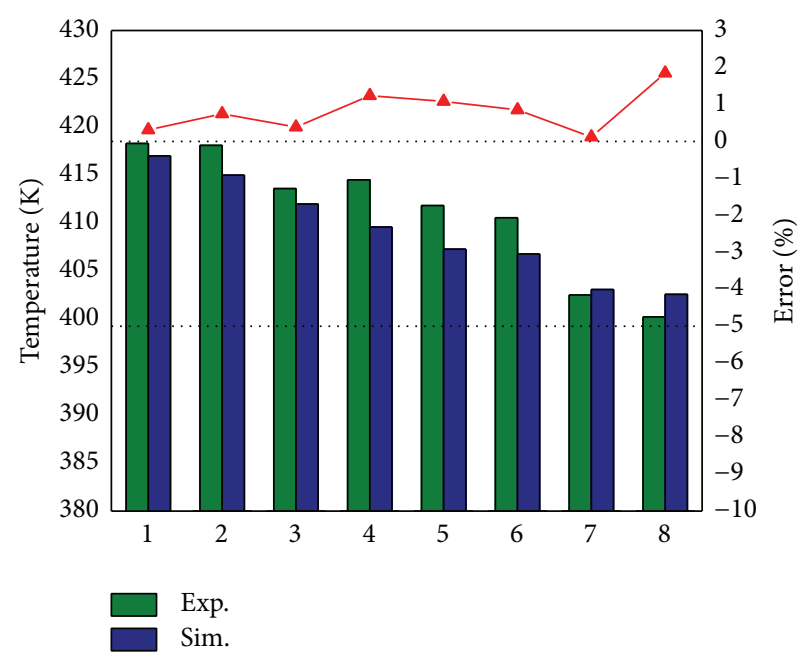

(b) $\mathrm{Cl}$

FIGURE 7: Temperature comparison at points 1-8 between the simulation and experiment under different conditions.

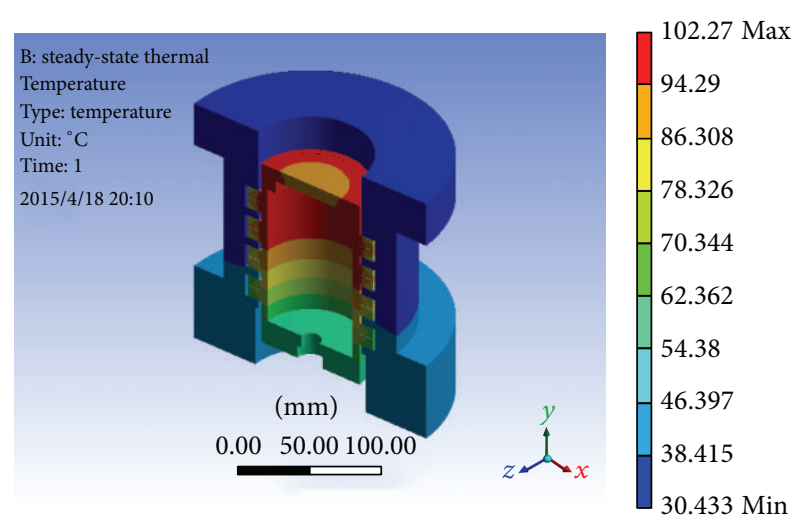

(a) Integration

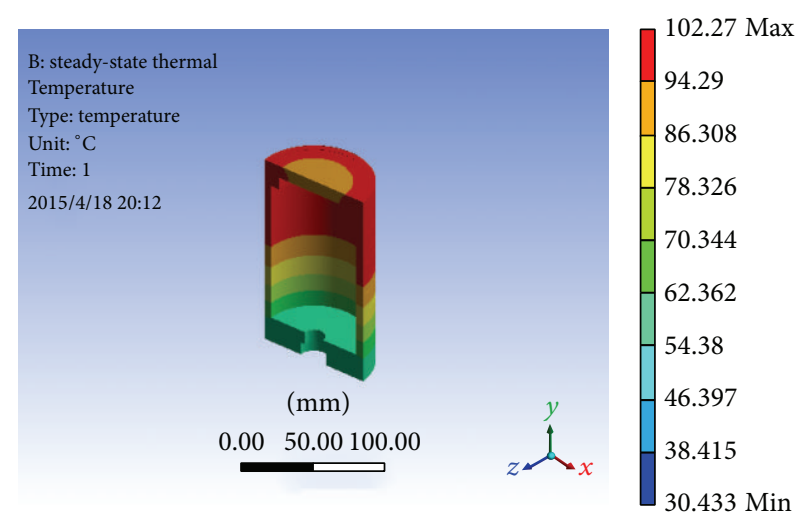

(b) Piston rod

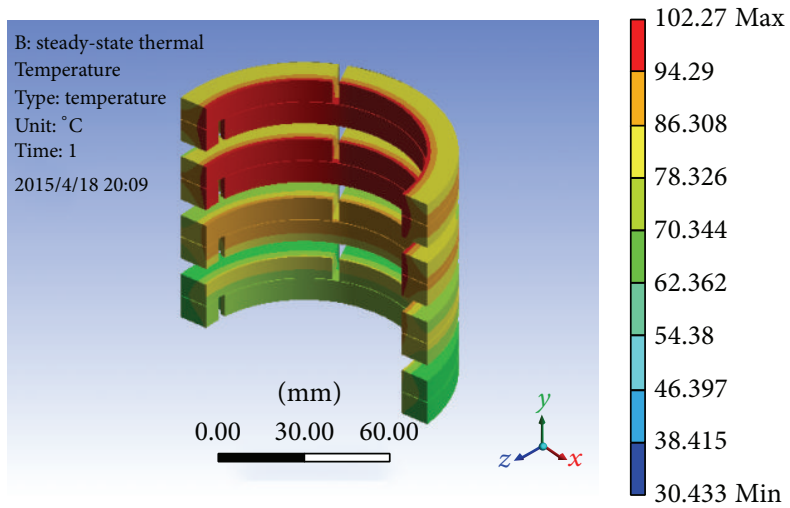

(c) Packing rings

FIgURE 8: Temperature distribution of modeling results under condition B3.

compression chamber puts the cover side in opposition to the frictional heat transfer. When frictional heat was transferred along the axle direction, this disadvantage made it harder for the heat to reach the cover side than the crank side, and therefore the temperature declined from packing ring
1 to 8 . The average deviation between the simulation and experimental results was $2.35 \%$, and the largest deviation was $4.81 \%$. The temperature distribution of the modeling results under condition B3 is presented in Figure 8. It can be seen that the maximum temperature of the piston rod and 


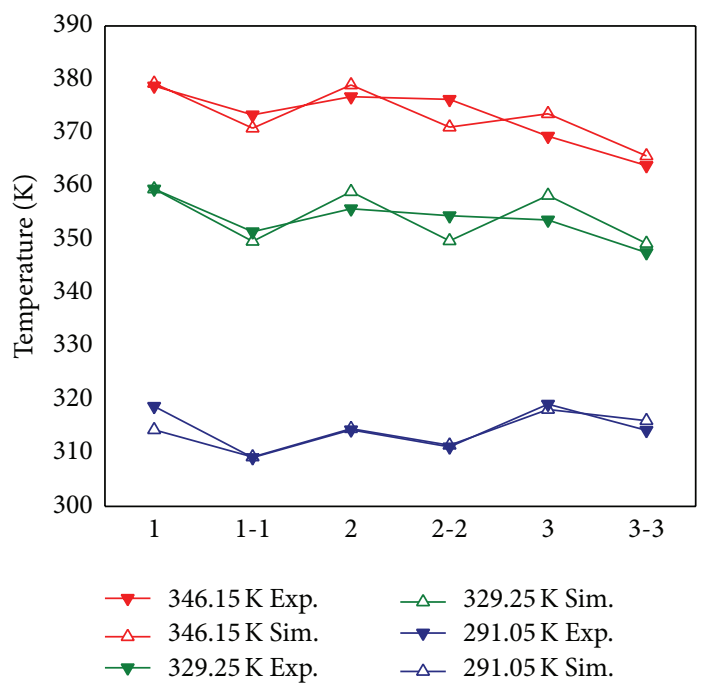

FIGURE 9: Radial temperature comparison between simulation and experiment at various discharge temperatures.

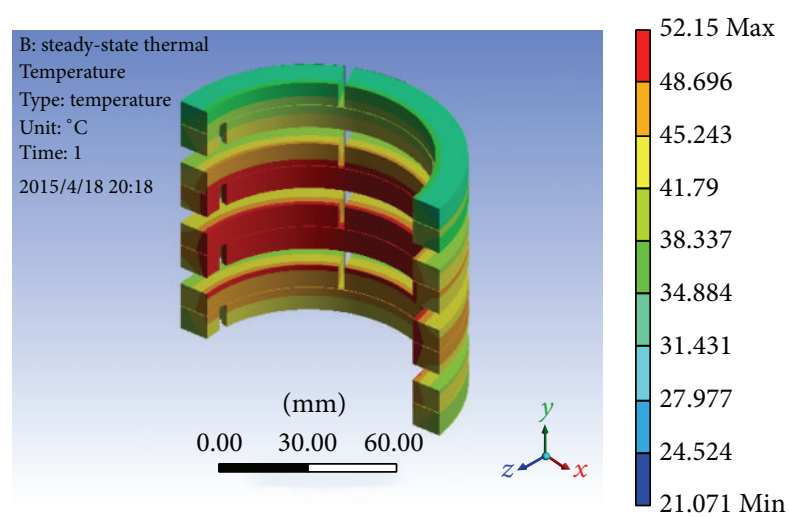

(a) D1: $291.05 \mathrm{~K}$

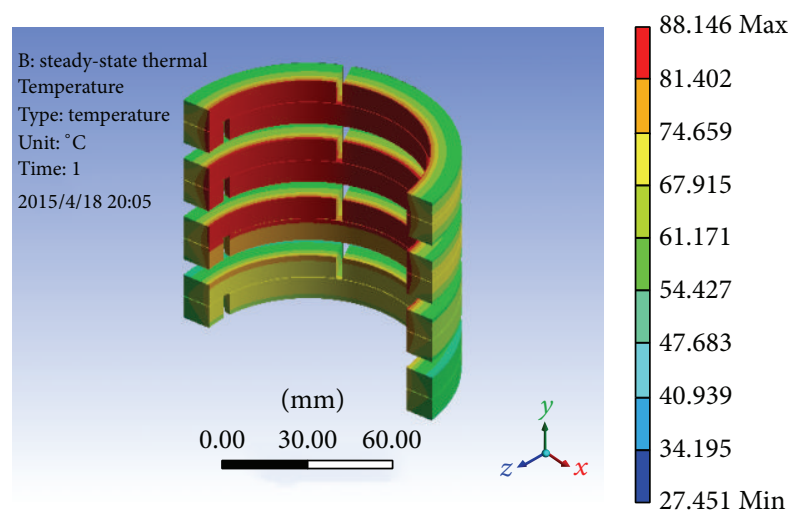

(b) D2: $329.25 \mathrm{~K}$

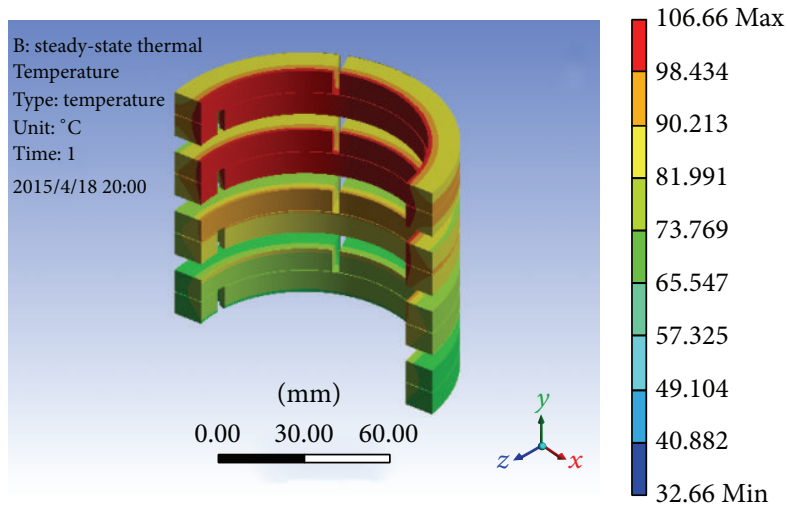

(c) $\mathrm{D} 3: 346.15 \mathrm{~K}$

FIGURE 10: Temperature distribution of the packing rings at various discharge temperatures.

packing rings was $375.42 \mathrm{~K}$. However, the temperatures of the cylinder and packing boxes were much lower, as shown in Figure 8(a).

4.1.2. Discharge Temperature Distribution. The radial temperature distribution is discussed in relation to various discharge temperatures (condition D). Figure 9 presents a comparison of the numerical simulation and experimental investigation results. The average and maximum deviation between those results was $1.21 \%$ and $1.38 \%$, respectively.

Figure 10 presents the simulation results of the three discharge temperatures in group D. At discharge temperatures of 


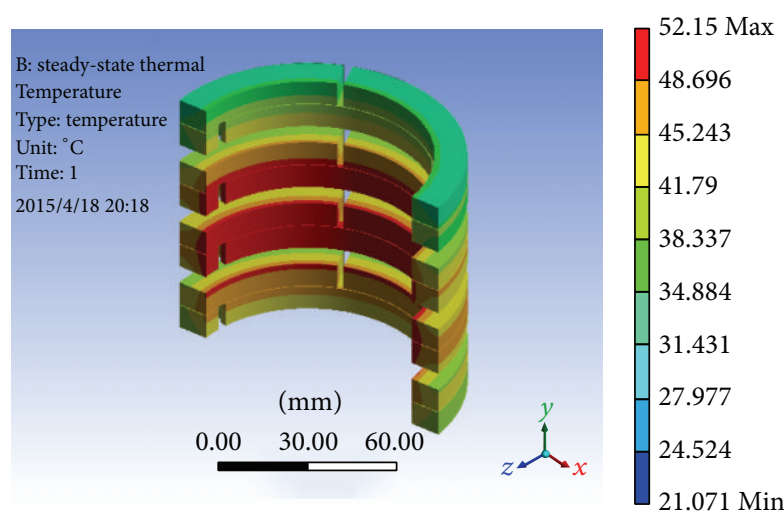

(a) B1: pressure ratio $=1.0$

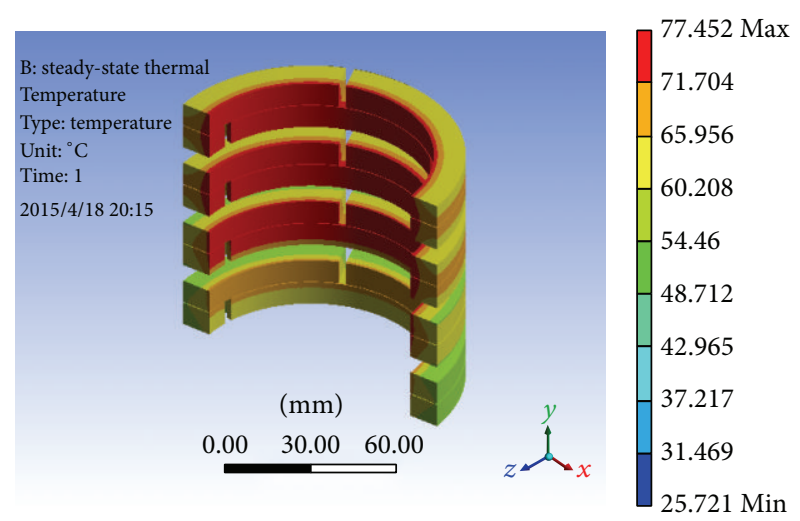

(b) $\mathrm{B} 2$ : pressure ratio $=1.8$

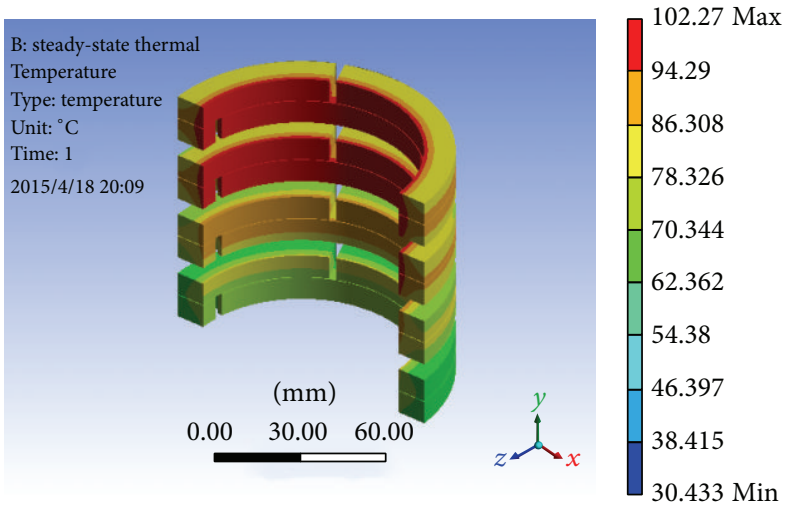

(c) B3: pressure ratio $=2.6$

FIGURE 11: Temperature distribution of packing rings at various pressure ratios.

291.05 K, $329.25 \mathrm{~K}$, and $346.15 \mathrm{~K}$, the maximum temperature gradients from the inner to outer surface of the packing rings were $6 \mathrm{~K}, 16.3 \mathrm{~K}$, and $13.8 \mathrm{~K}$, respectively. The highest temperatures in the integration of the packing box, piston rod, and cylinder were $324.25 \mathrm{~K}, 359.45 \mathrm{~K}$, and $378.75 \mathrm{~K}$, respectively.

The comparison of the packing rings' temperature distributions along the radial and axial directions revealed a high level of agreement between the simulation results and experimental data.

\subsection{Factors Influencing Temperature Distribution of Packing Rings}

4.2.1. Pressure Ratio. Figure 11 presents the temperature distribution of the packing rings at various pressure ratios (condition $\mathrm{B}$ ). The results indicate that the maximum temperature occurred at packing ring 6 when the pressure ratio was lower and at packing ring 1 when it was higher, which is similar to the group D results shown in Figure 10. The discharge temperature rose with an increase in the pressure ratio in the same condition. Figure 12 shows the measured temperatures of packing rings $1-8$ in group $\mathrm{B}$. Under condition $\mathrm{B} 1$, the pressure ratio was 1.0 , and the discharge temperature was $291.05 \mathrm{~K}$. The gas temperature was low and had little effect on the frictional heat transfer. The cover side in contact

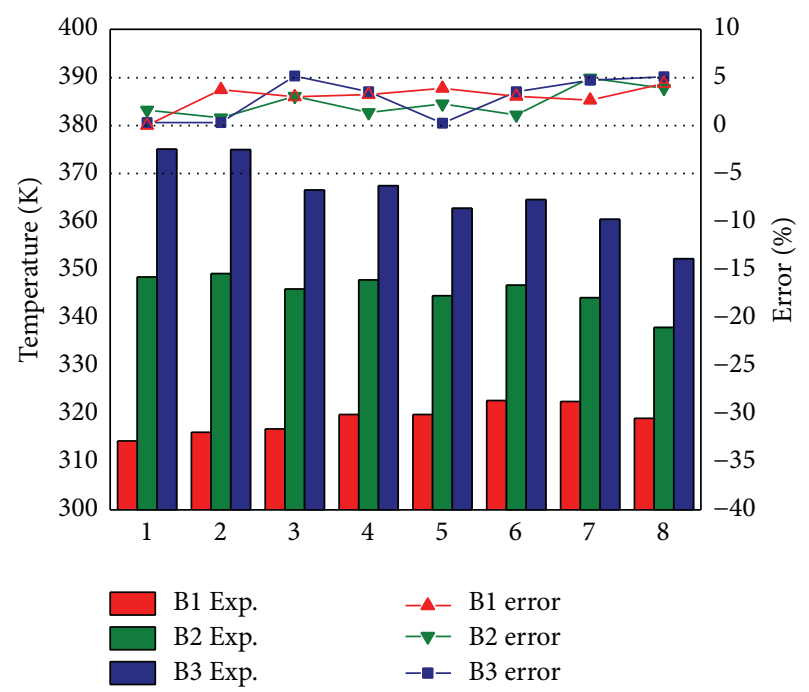

FIGURE 12: Temperature of axial test points and simulation error in group $\mathrm{B}$.

with the environment was cooler than the crank side, which made it easy for frictional heat to conduct to the cover side. Hence, the highest temperature was found at packing ring 6. Under condition B3, the boundary condition of strong heat convection between the high-temperature compressed gas and compression chamber placed the cover side in 


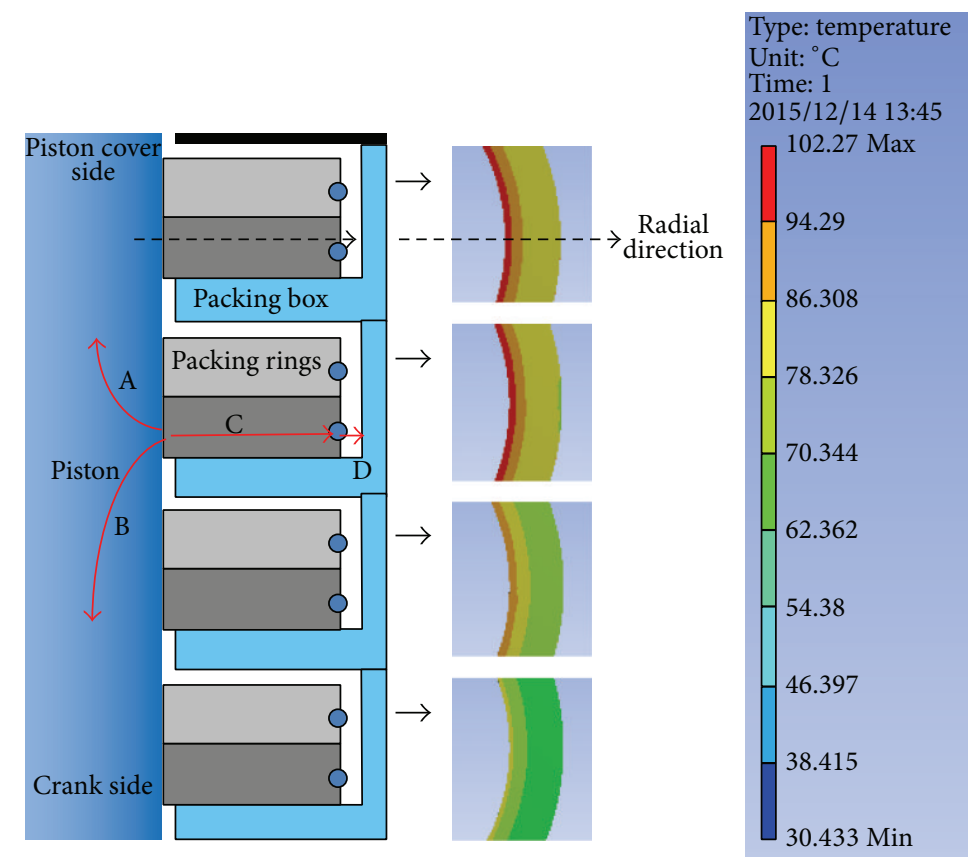

FIGURE 13: Radial temperature of packing rings and the frictional heat transfer in B3.

opposition to the frictional heat transfer, thereby aggravating the pressure ratio, which increased with an increase in discharge temperature. Therefore, the temperature decreased from packing ring 1 to 8 . Under discharge temperature conditions of $291.05 \mathrm{~K}, 323.35 \mathrm{~K}$, and $337.65 \mathrm{~K}$, the temperature gradients from the inner to outer surface were $6 \mathrm{~K}, 9.8 \mathrm{~K}$, and 12.7 K, respectively. The discharge temperature and frictional heat flux increased when the pressure ratio rose from 1.0 to 2.6. The heat convection between the high-temperature compressed gas and compression chamber had a greater influence on the temperature distribution of the packing rings when the pressure ratio was higher.

Figure 13 illustrates the temperature changes of packing rings 1, 3, 5, and 7 along the radial direction under condition B3. The radial temperature distribution of each packing ring was consistent in this condition. The majority of the temperature decline along the radial direction occurred in the third of the area closest to the friction contact surface. The inner surface had the highest temperature, which was the main reason for the high-temperature thermal failure of the packing rings. The friction heat generated from the movement within the friction pair (i.e., the packing rings and piston rod) accumulated at the contact surface. The red lines in Figure 13 show the three main areas of thermal resistance against heat transfer. The first area is found in the packing rings marked $\mathrm{C}$. These packing rings were made of plastic material such as PTFE, which does not readily conduct heat. The second area is between the packing rings and packing box, marked D. In this area, heat transfer was prevented by the low heat exchange capacity of the air. The third is the piston area. Although a piston made from metal has good thermal conductivity, it does not exhibit good heat conduction along the radial direction, as the other side is exposed to friction heat. Hence, in this study, heat conduction

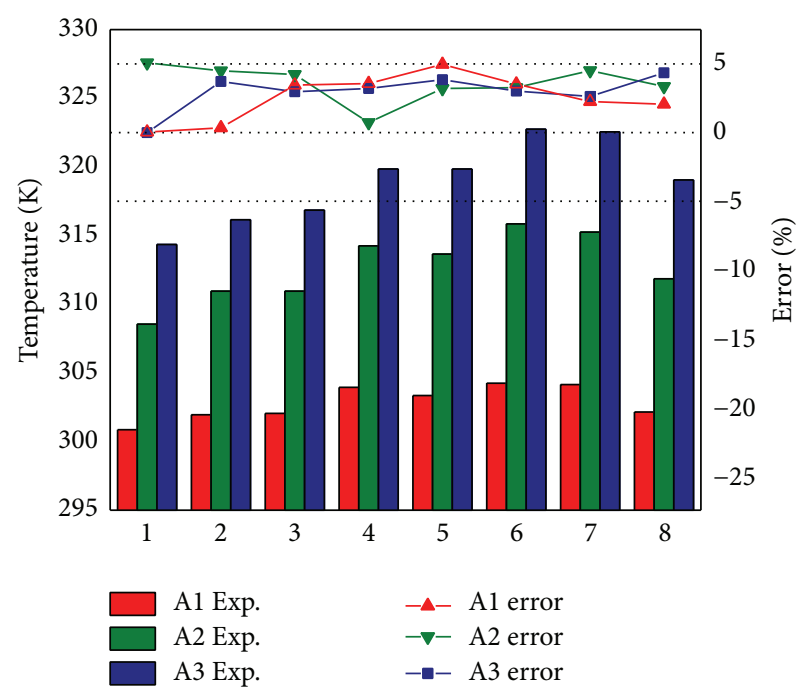

FIgURE 14: Temperature of axial test points and simulation error in group A.

in the A-B direction was restricted by the piston boundary condition.

4.2.2. Compressor Rotational Speed. The influence of the compressor's rotational speed on the temperature distribution of the packing rings was analyzed by comparing the simulation and experimental results under condition A. As discussed above, the pressure ratio determines where the maximum temperature occurs. When the pressure ratio was kept at 1.0, the maximum temperature of the packing rings occurred at packing ring 6 , and the temperature at the cover side was lower than that at the crank side. As shown in Figure 14, the temperature gradients in the radial 


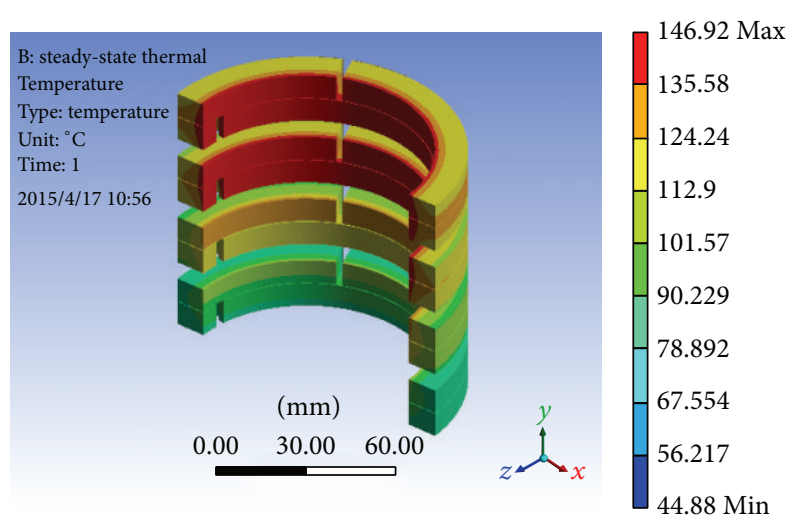

(a) $\mathrm{Cl}$ : natural cooling

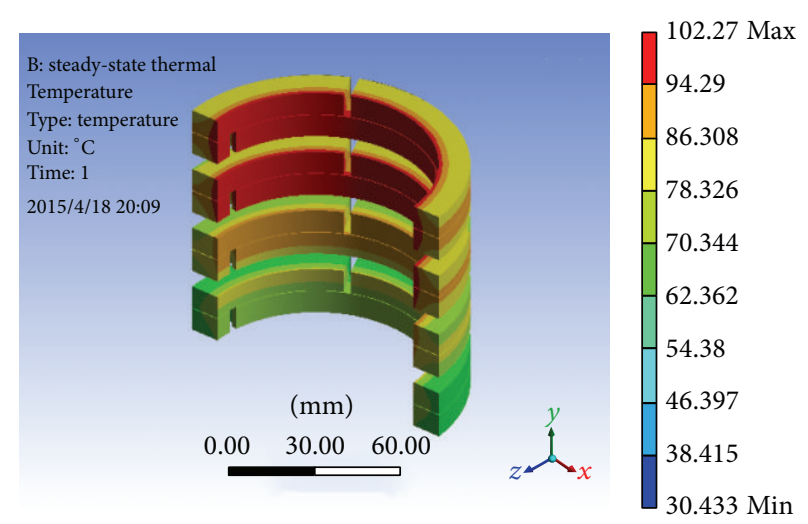

(b) $\mathrm{C} 2: 1880 \mathrm{~m}^{3} \cdot \mathrm{h}^{-1}$

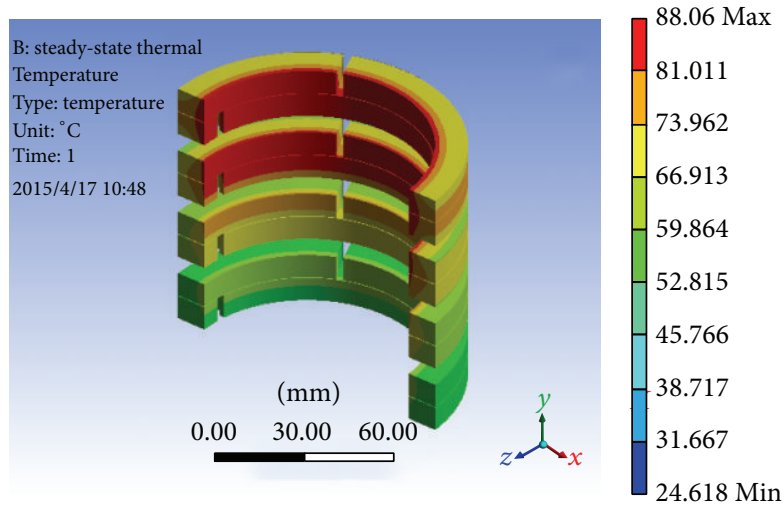

(c) C3: $3000 \mathrm{~m}^{3} \cdot \mathrm{h}^{-1}$

FIGURE 15: Temperature distribution of packing rings under various external cooling conditions.

direction were $3.3 \mathrm{~K}, 4.5 \mathrm{~K}$, and $6 \mathrm{~K}$, respectively, whereas the compressor rotational speeds were $580 \mathrm{r} \cdot \mathrm{min}^{-1}, 1015 \mathrm{r} \cdot \mathrm{min}^{-1}$, and $1450 \mathrm{r} \cdot \mathrm{min}^{-1}$. The temperature gradients underwent an obvious increase with an increase in the compressor's rotational speed because the frictional heat is directly proportional to that speed, according to (1). The shorter cycle meant that there was insufficient time for frictional heat transfer. Thus, the average temperature of the packing rings increased when the compressor's rotational speed increased. The highest temperature of the packing rings increased from $304.25 \mathrm{~K}$ to $322.75 \mathrm{~K}$ when the rotational speed increased from $580 \mathrm{r} \cdot \mathrm{min}^{-1}$ to $1450 \mathrm{r} \cdot \mathrm{min}^{-1}$.

4.2.3. External Cooling Conditions. Figure 15 illustrates the temperature distribution of the packing rings in various external cooling conditions (condition C). It can be seen that the axial temperature decreased from the cover side to the crank side due to the higher pressure ratio in condition C. That tendency was in accord with the conclusion reached concerning the pressure ratio's influence. However, the highest packing ring temperatures were $416.95 \mathrm{~K}, 373.45 \mathrm{~K}$, and $361.25 \mathrm{~K}$ under the natural cooling, $1880 \mathrm{~m}^{3} \cdot \mathrm{h}^{-1}$ air cooling, and $3000 \mathrm{~m}^{3} \cdot \mathrm{h}^{-1}$ air cooling conditions, respectively, and the respective temperature gradients were $17.3 \mathrm{~K}, 12.7 \mathrm{~K}$, and $11.0 \mathrm{~K}$. These results demonstrate that external cooling conditions have great influence on packing ring temperature. The external cooling conditions were measured by the convective

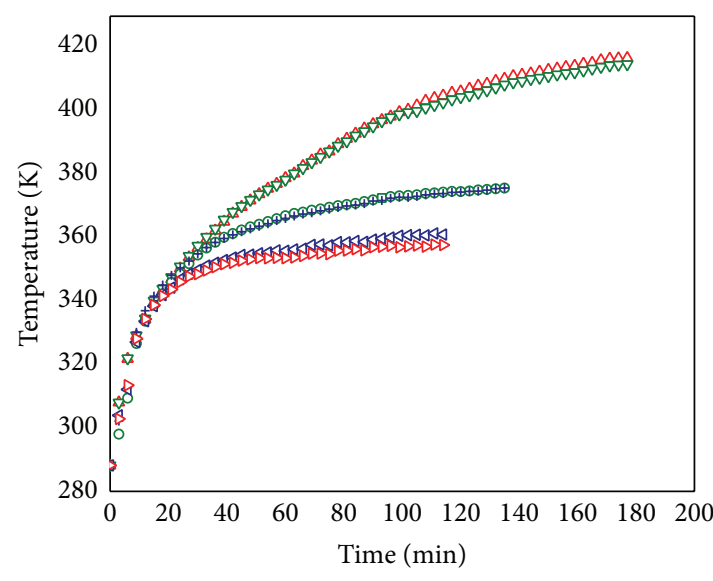

$$
\begin{array}{ll}
\triangle \text { Point } 1 \text { (natural cooling) } & + \text { Point } 2\left(1880 \mathrm{~m}^{3} \cdot \mathrm{h}^{-1}\right) \\
\nabla \text { Point } 2 \text { (natural cooling) } & \triangleleft \text { Point } 1\left(3000 \mathrm{~m}^{3} \cdot \mathrm{h}^{-1}\right) \\
\triangle \text { Point } 1\left(1880 \mathrm{~m}^{3} \cdot \mathrm{h}^{-1}\right) & \triangleright \text { Point } 2\left(3000 \mathrm{~m}^{3} \cdot \mathrm{h}^{-1}\right)
\end{array}
$$

FIgURE 16: Test temperature variation of packing rings in group C.

heat transfer coefficient. Increasing the cooling wind speed caused a significant reduction in the average temperature, but the influence of external cooling declined with an increase in that speed.

Figure 16 presents the test temperature changes of packing rings 1 and 2 . It took 179 minutes for the packing rings 


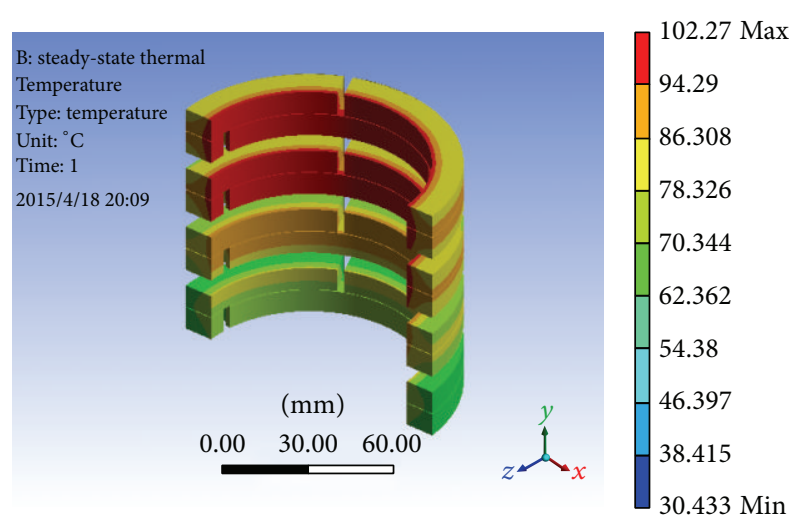

(a) Carbon fiber-filled PTFE

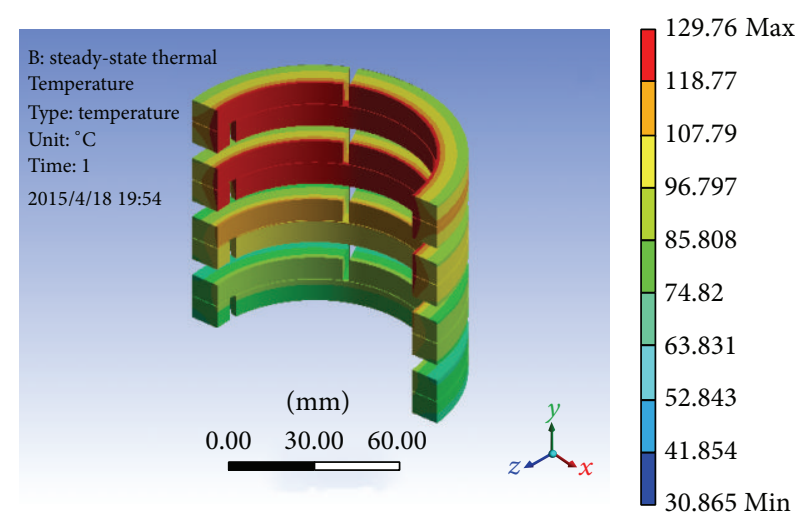

(b) Victrex-450GL30

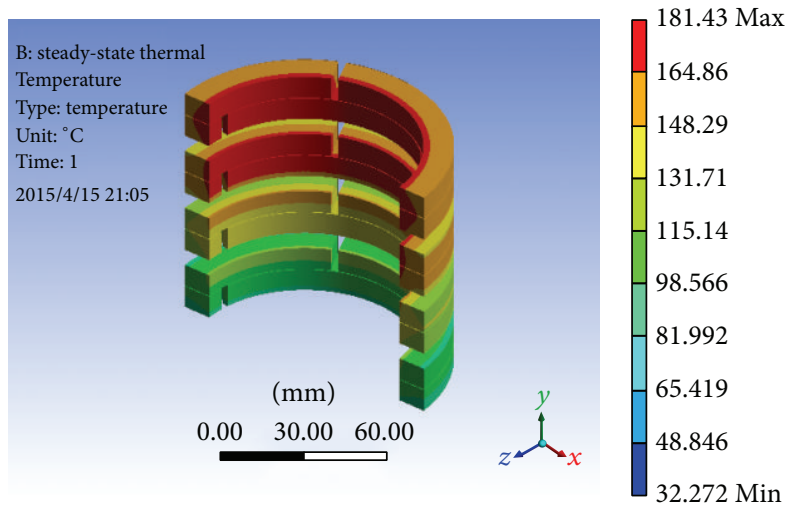

(c) Victrex-450CA30

FIGURE 17: Temperature distribution of packing rings made from various materials.

to reach a stable temperature of $418.25 \mathrm{~K}$ under natural cooling, 136 minutes under $1880 \mathrm{~m}^{3} \cdot \mathrm{h}^{-1}$ air cooling, and 115 minutes under $3000 \mathrm{~m}^{3} \cdot \mathrm{h}^{-1}$ air cooling. These results suggest that better external cooling conditions are conducive to frictional heat transfer and allow the quick stabilization of a compressor's internal temperature.

4.2.4. Packing Ring Material. To investigate the effect of packing ring material on the temperature distribution, three self-lubricating materials were applied in the finite element model: carbon fiber-filled PTFE (PTFE+CF) and two other types of PTFE (Victrex-450GL30, Victrex-450CA30). The thermochemical properties of these materials are presented in Table 7. The model was simulated under the group B3 condition, and the pressure ratio was set at 2.6 to ensure that the axial temperature decreased from the cover side to the crank side.

Figure 17 illustrates the temperature distribution of the packing rings made from various materials. It can be seen that the temperature gradients from the inner to outer surfaces of the packing rings were $12.3 \mathrm{~K}, 20.1 \mathrm{~K}$, and $17.9 \mathrm{~K}$, respectively. These gradients had a direct correlation with the frictional heat transfer, which was relative to the heat conductivity coefficient and friction coefficient. The friction and heat conductivity coefficients of GL30 were 1.45 times and 0.86 times those of PTFE+CF. Therefore, the temperature gradient
TABLE 7: Thermochemical properties of different self-lubricating materials.

\begin{tabular}{|c|c|c|c|}
\hline Property & PTFE+CF & Victrex-450GL30 & Victrex-450CA30 \\
\hline $\begin{array}{l}\text { Friction } \\
\text { coefficient }\end{array}$ & 0.11 & 0.16 & 0.26 \\
\hline Density $\left(\mathrm{kg} \cdot \mathrm{m}^{3}\right)$ & 2040 & 1510 & 1410 \\
\hline $\begin{array}{l}\text { Specific heat } \\
\left(\mathrm{J} \cdot \mathrm{K}^{-1} \cdot \mathrm{kg}^{-1}\right)\end{array}$ & 1050 & 1700 & 1800 \\
\hline $\begin{array}{l}\text { Thermal } \\
\text { conductivity } \\
\left(\mathrm{W} \cdot \mathrm{m}^{-1} \cdot \mathrm{K}^{-1}\right)\end{array}$ & 0.5 & 0.43 & 0.92 \\
\hline
\end{tabular}

was calculated as $1.45 / 0.86$ times (i.e., 1.68 times), which is equal to $20.1 \mathrm{~K} / 12.3 \mathrm{~K}$. Similarly, the friction and heat conductivity coefficients of CA30 were 2.36 and 1.84 times those of PTFE+CF. Hence, the temperature gradient along the radial direction of the packing rings made of CA30 was 1.45 times that of those made of PTFE+CF.

\section{Conclusion}

The main objective of this study was to analyze the dynamic temperature distribution of the packing rings in an oil-free 
compressor during compressor operation. A test rig incorporating an innovative device for measuring the dynamic temperature distribution inside the packing rings was designed and constructed, and a 3D heat transfer model was developed to investigate the temperature distribution. Furthermore, packing rings' influence on the temperature distribution has been discussed in detail herein. The study's main findings are summarized as follows.

(1) The maximum temperature difference between the simulation and experimental results was $6.8 \mathrm{~K}$, and the average deviation was less than $2.35 \%$, suggesting that the simulation results are reliable.

(2) The radial temperature distribution followed a similar trend for the four sets of packing rings investigated. The third of the packing ring area closest to the friction contact surface featured the largest temperature gradient in the radial direction. The inner surface had the highest temperature, which was the main reason for the high-temperature thermal failure of the packing rings.

(3) The pressure ratio exerted a significant effect on the axial temperature distribution: the higher the pressure ratio, the higher the discharge temperature. The maximum axial temperature occurred at packing ring 1 , and the temperature decreased from the cover side to the crank side. However, at a lower pressure ratio, the maximum temperature occurred at packing ring 6 and decreased on both sides.

(4) The average temperature declined significantly with an improvement in the external cooling conditions. The maximum temperatures of the packing rings were $416.95 \mathrm{~K}, 373.45 \mathrm{~K}$, and $361.25 \mathrm{~K}$ under natural cooling, $1880 \mathrm{~m}^{3} \cdot \mathrm{h}^{-1}$ air cooling, and $3000 \mathrm{~m}^{3} \cdot \mathrm{h}^{-1}$ air cooling, respectively. The ring temperature increased from $304.25 \mathrm{~K}$ to $322.75 \mathrm{~K}$ when the rotational speed of the compressor increased from $580 \mathrm{r} \cdot \mathrm{min}^{-1}$ to $1450 \mathrm{r} \cdot \mathrm{min}^{-1}$.

(5) The packing ring material had a direct effect on the temperature gradients due to the influence of frictional heat transfer, which was determined by the heat conductivity and friction coefficients of the material.

\section{Nomenclature}
$P$ : $\quad$ Pressure $/ \mathrm{MPa}$
$T$ : Temperature/K
$q$ : Frictional heat flux $/ \mathrm{W} \cdot \mathrm{m}^{-2}$
$v$ : Velocity $/ \mathrm{m} \cdot \mathrm{s}^{-1}$
$c_{p}$ : Specific heat at constant pressure $/ \mathrm{J} \cdot \mathrm{kJ}^{-1} \cdot \mathrm{K}^{-1}$
$h_{w}$ : Convective heat transfer coefficient $/ \mathrm{W} \cdot \mathrm{m}^{-2} \cdot \mathrm{K}^{-1}$
$V_{p}$ : Average velocity of piston $\mathrm{rod} / \mathrm{m} \cdot \mathrm{s}^{-1}$
$\lambda$ : Heat conductivity coefficient $/ \mathrm{W} \cdot \mathrm{m}^{-1} \cdot \mathrm{K}^{-1}$

$\gamma$ : Heat partition coefficient

$\rho:$ Density/ $\mathrm{kg} \cdot \mathrm{m}^{-3}$

$\tau$ : Time/s

$\Phi$ : Heating rate of inner heat source $/ \mathrm{W} \cdot \mathrm{m}^{-3}$

$\mu_{f}$ : Friction coefficient.

\section{Competing Interests}

The authors declare that there is no conflict of interests regarding the publication of this paper.

\section{Acknowledgments}

The study presented in this paper was supported by funding from the National Natural Science Foundation of China (Research Project no. 51175407).

\section{References}

[1] J. P. Davim and R. Cardoso, "Effect of the reinforcement (carbon or glass fibres) on friction and wear behaviour of the PEEK against steel surface at long dry sliding," Wear, vol. 266, no. 7-8, pp. 795-799, 2009.

[2] A. Mimaroglu, H. Unal, and T. Arda, "Friction and wear performance of pure and glass fibre reinforced poly-ether-imide on polymer and steel counterface materials," Wear, vol. 262, no. 11-12, pp. 1407-1413, 2007.

[3] C. Radcliffe, "Sealing material developments for reciprocating gas compressors," Sealing Technology, vol. 2005, no. 11, pp. 7-11, 2005.

[4] C. Kowandy, C. Richard, and Y. M. Chen, "Characterization of wear particles for comprehension of wear mechanisms. Case of PTFE against cast iron," Wear, vol. 265, no. 11-12, pp. 1714-1719, 2008.

[5] S. Zhu, L. Kong, F. Li et al., "NiAl matrix self-lubricating composite at a wide temperature range," Journal of Tribology, vol. 137, no. 2, Article ID 021301, 2015.

[6] W. Okularczyk, "Experimental investigations of guide rings made of UHMWPE and PTFE composite in water hydraulic systems," Archives of Civil and Mechanical Engineering, vol. 7, no. 4, pp. 167-176, 2007.

[7] D. Xin, J. Feng, L. Ding, D. Yang, and X. Peng, "Experimental investigation of pressure distribution between the piston rings and its formation in reciprocating compressors," Journal of Mechanical Engineering Science, vol. 226, no. 11, pp. 2701-2712, 2012.

[8] S. Pengyun, C. Kuangmin, and D. Zongyun, "A theoretical analysis of the lateral pressure coefficients in a soft-packed stuffing-box seal," Tribology International, vol. 30, no. 10, pp. 759-765, 1997.

[9] M. Diany and A.-H. Bouzid, "Analytical evaluation of stresses and displacements of stuffing-box packing based on a flexibility analysis," Tribology International, vol. 42, no. 6, pp. 980-986, 2009.

[10] M. Diany and A. H. Bouzid, "Short term relaxation of stuffing box packings," in Proceedings of the Pressure Vessels and Piping Division Conference (ASME '07), pp. 1-6, San Antonio, Tex, USA, 2007.

[11] M. Kazeminia and A.-H. Bouzid, "Stress analysis of packed stuffing-boxes," Journal of Pressure Vessel Technology, vol. 137, no. 5, Article ID 051205, 2015. 
[12] M. Kazeminia and A.-H. Bouzid, "Analysis of stresses and strains in packed stuffing-boxes," in Proceedings of the ASME Pressure Vessels and Piping Conference (PVP '14), pp. 1-11, Anaheim, Calif, USA, July 2014.

[13] M. Kazeminia and A.-H. Bouzid, "Analytical and numerical evaluation of the axial stress distribution of two soft-packed stuffing-box configurations," in Proceedings of the ASME Turbo Expo 2014: Turbine Technical Conference and Exposition, pp. 1-8, Düsseldorf, Germany, June 2014.

[14] C. D. Girão and K. Guenther, "Evaluation of stuffing box forces associated with the thermal expansion of e-PTFE and graphite packing sets," in Proceedings of the ASME Pressure Vessels and Piping Conference (PVP '12), pp. 167-173, Toronto, Canada, July 2012.

[15] J. C. Veiga, A. S. Carmo, C. D. Girao et al., "The influence on the stuffing box of the forces generated by packing thermal expansion," in Proceedings of the Pressure Vessels Piping Division Conference (ASME '11), pp. 227-233, Baltimore, Md, USA, July 2011.

[16] R. Rabuté and T. Tian, "Challenges involved in piston top ring designs for modern SI engines," Journal of Engineering for Gas Turbines and Power, vol. 123, no. 2, pp. 448-459, 2001.

[17] H. Kruse, Calculation of the Hydrodynamic Lubrication of Piston and Piston Rings in Refrigeration Compressors, Purdue University, West Lafayette, Ind, USA, 1974.

[18] U. Todsen and H. Kruse, Hydrodynamic Optimization of the Tribological System Piston-Ring-Liner, Purdue, West Lafayette, Ind, USA, 1982.

[19] P. Obert, T. Müller, H.-J. Füßer, and D. Bartel, "The influence of oil supply and cylinder liner temperature on friction, wear and scuffing behavior of piston ring cylinder liner contacts-a new model test," Tribology International, vol. 94, pp. 306-314, 2016.

[20] S. Johansson, C. Frennfelt, A. Killinger, P. H. Nilsson, R. Ohlsson, and B. G. Rosén, "Frictional evaluation of thermally sprayed coatings applied on the cylinder liner of a heavy duty diesel engine: pilot tribometer analysis and full scale engine test," Wear, vol. 273, no. 1, pp. 82-92, 2011.

[21] S. Johansson, P. H. Nilsson, R. Ohlsson, and B.-G. Rosén, "Experimental friction evaluation of cylinder liner/piston ring contact," Wear, vol. 271, no. 3-4, pp. 625-633, 2011.

[22] J. Polman, "Heat transfer in a piston cylinder system," International Journal of Heat and Mass Transfer, vol. 24, no. 1, pp. 184187, 1981.

[23] V. P. Singh, P. C. Upadhyay, and N. K. Samria, "Some heat transfer studies on a diesel engine piston," International Journal of Heat and Mass Transfer, vol. 29, no. 5, pp. 812-814, 1986.

[24] Y. H. Shen, B. Zhang, D. B. Xin, D. Yang, and X. Peng, "3-D finite element simulation of the cylinder temperature distribution in boil-off gas (BOG) compressors,' International Journal of Heat and Mass Transfer, vol. 55, no. 23-24, pp. 7278-7286, 2012.

[25] J. J. Truhan, J. Qu, and P. J. Blau, "A rig test to measure friction and wear of heavy duty diesel engine piston rings and cylinder liners using realistic lubricants," Tribology International, vol. 38, no. 3, pp. 211-218, 2005.

[26] A. A. Yevtushenko and M. Kuciej, "Influence of the protective strip properties on distribution of the temperature at transient frictional heating," International Journal of Heat and Mass Transfer, vol. 52, no. 1-2, pp. 376-384, 2009.

[27] K. Murai and K. Nagura, "Kobe steel works engineering reports," LNG Boil-Off Gas Reciprocating Compressors, vol. 49, no. 1, pp. 64-67, 1999.
[28] International Organization for Standardization (ISO), Guide to the Expression of Uncertainty in Measurement, International Bureau of Weights and Measures, ISO, Geneva, Switzerland, 1995. 


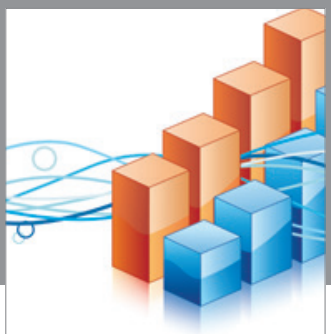

Advances in

Operations Research

vatem alat4

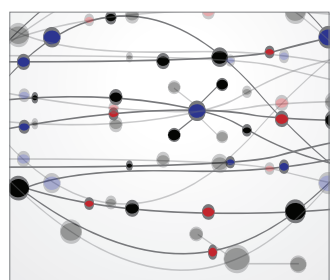

\section{The Scientific} World Journal
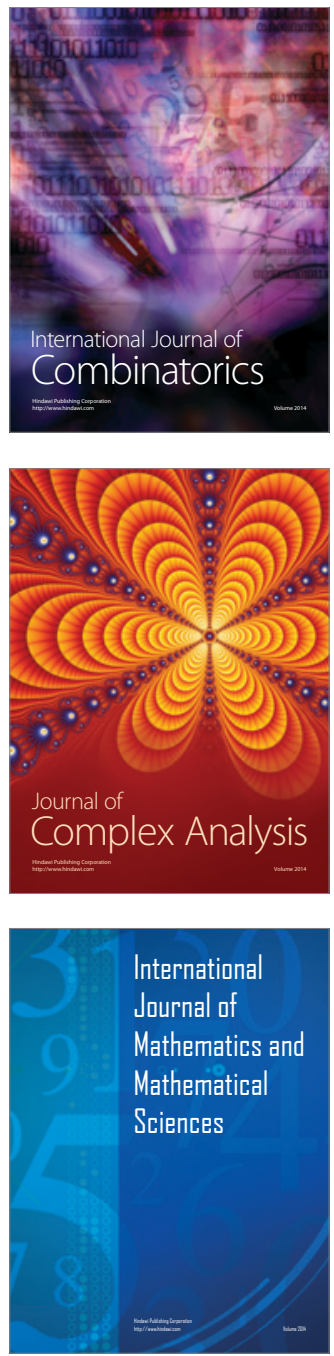
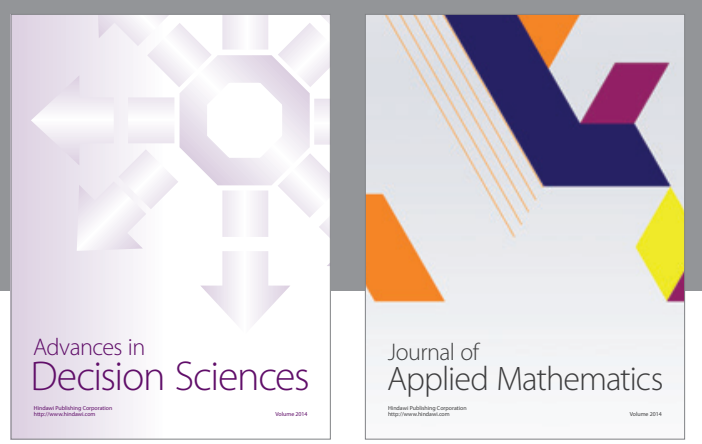

Algebra

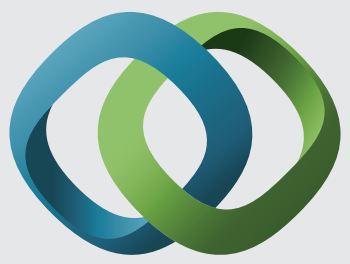

\section{Hindawi}

Submit your manuscripts at

http://www.hindawi.com
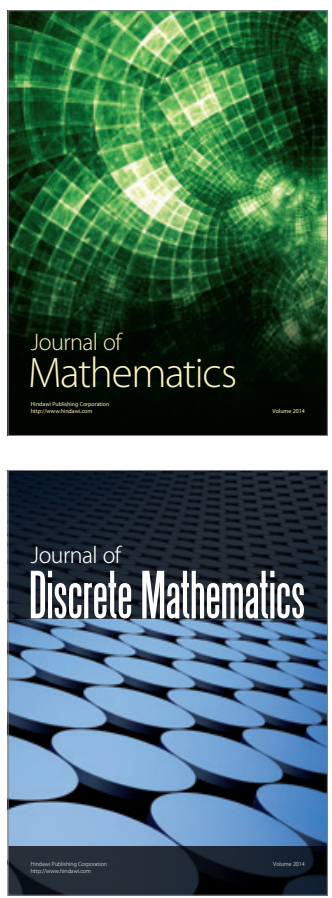

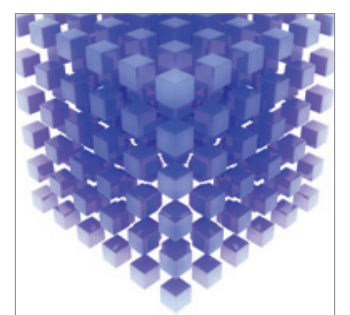

Mathematical Problems in Engineering
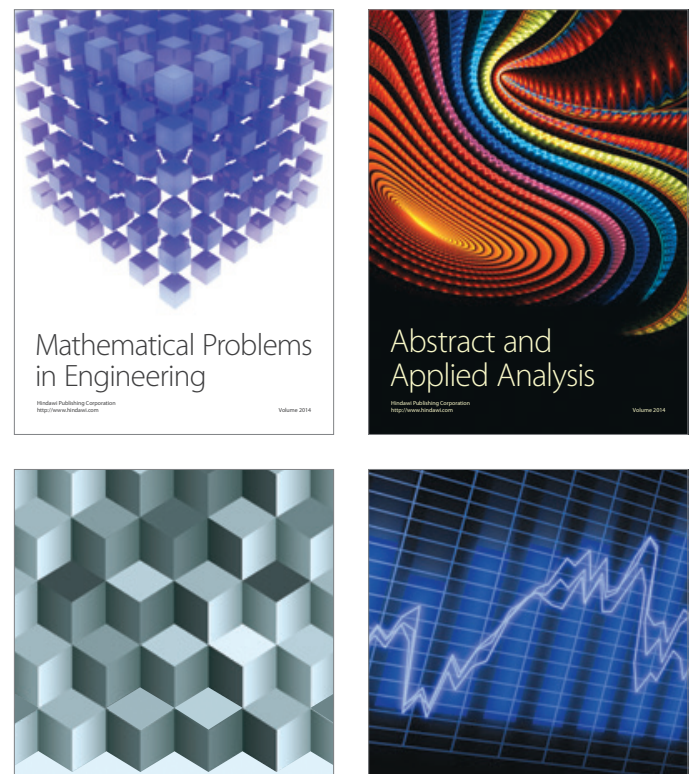

Journal of

Function Spaces

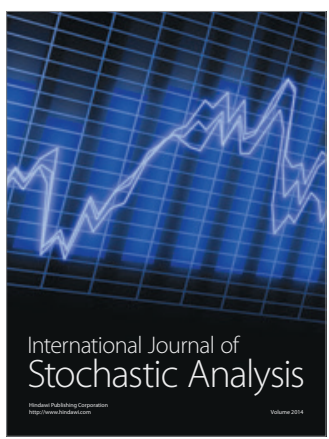

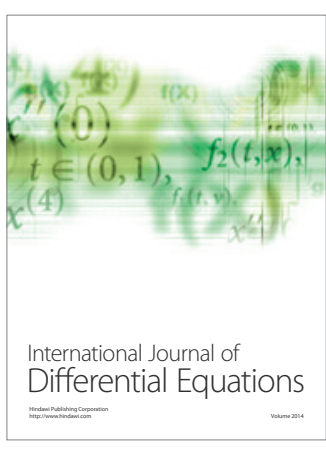
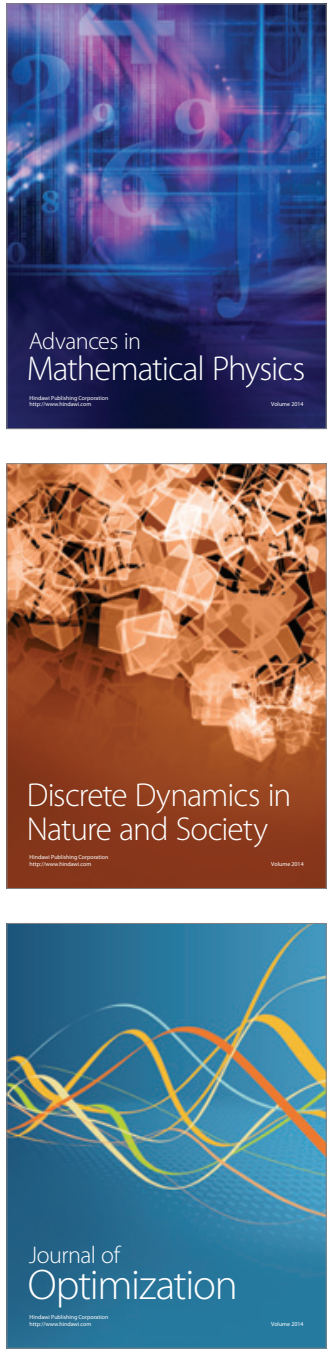